\title{
OS DESAFIOS DE MINISTRAR AULAS PARA IDOSOS/AS
}

\section{THE CHALLENGES OF TEACHING FOR THE ELDERLY}

\section{LOS DESAFÍOS DE MINISTRAR CLASES PARA ADULTOS MAYORES}

Marina Holanda Kunst

\begin{abstract}
Resumo: Diante de um cenário de crescente número de idosos em todo o mundo, pensar nesses sujeitos torna-se fundamental para a construção de um mundo apto para recebe-los, respeitando suas capacidades e dificuldades inerentes a idade. Destaca-se, assim, a educação, por possibilitar que esses sujeitos tenham mais autonomia e independência, tanto no espaço individual como no social. Dentro desta, depreende-se o ensino da língua espanhola para idosos como forma de fortalece-los, além da troca de experiência entre aluno-professor. Dentro desse contexto, a UnATI/UFPE se destaca por promover e incentivar ações para melhoria da qualidade de vida das pessoas idosas. A presente pesquisa é um relato de experiência da pesquisadora no período em que era professora na UnATI/UfPE. O trabalho tem por objetivo refletir sobre a utilização de material didático para classes de espanhol para idosos. A partir de observações feitas pela professora e por algumas sugestões dos próprios alunos ao longo do curso, a professora começou a refletir sobre novas ferramentas facilitadores para a assimilação e aprendizagem da língua espanhola em aula. Diante desses acontecimentos, a professora tentou incorporar outros tipos de materiais didáticos, como os lúdicos, vídeos e músicas/canção, como forma de envolver e motivar os alunos nas aulas. Dessa forma, o ensino da língua espanhola na UnATI/UFPE é uma das formas de empoderar os idosos. Salienta-se assim, o uso do livro e a dificuldade de envolvimento da turma a partir deste, mostrando-se necessário o uso de incorporação de novas técnicas para motivar os alunos.
\end{abstract}

Palavras-chave: Espanhol. UnATI. Material didático.

Abstract: Faced with a scenario of increasing numbers of elderly people worldwide, thinking about these subjects becomes fundamental for the construction of a world apt to receive them, respecting their abilities and difficulties inherent in their age. Thus, education is emphasized, since it enables these subjects to have more autonomy and independence, both in the individual and in the social space. Within this, it is evident the teaching of the Spanish language for the elderly is a way to strengthen them, besides the exchange of experience between student-teacher. Within this context, UnATI / UFPE stands out for promoting and encouraging actions to improve the quality of life of the elderly. The present research is an experience report of the researcher during the period in which she was a professor at UnATI / UfPE. This study aims to reflect on the use of didactic material for Spanish classes for the elderly. From the observations made by the teacher and some suggestions from students themselves throughout the course, the teacher began to reflect on new tools to facilitate the assimilation and learning of the Spanish language in class. Faced with these events, the teacher tried to incorporate other types of didactic material, such as games, videos and music / song, as a way to engage and motivate students in class. Thus, the teaching of the Spanish language in UnATI / UFPE is one of the ways to empower the

\footnotetext{
* Mestre em Desenvolvimento Urbano pela UFPE, com ênfase em edificação, acessibilidade e idoso. Professora da Universidade Aberta para a Terceira Idade (UnATI - UFPE), no curso de Espanhol. E-mail: marinakunst7@ hotmail.com
} 
elderly. It is emphasized, therefore, the use of the book and the difficulty of the involving the class from this one, it shows to be necessary the use of incorporation of new techniques to motivate the students.

Keywords: Spanish. UnATI. Pedagogic material.

Resumen: Ante un escenario de creciente número de ancianos en todo el mundo, pensar en esos sujetos se vuelve fundamental para la construcción de un mundo apto para recibirlos, respetando sus capacidades y dificultades inherentes a la edad. Se destaca, así, la educación, por posibilitar que esos sujetos tengan más autonomía e independencia, tanto en el espacio individual y en el social. Dentro de ésta, se desprende la enseñanza de la lengua española para ancianos como forma de fortalecerlos, además del intercambio de experiencia entre alumno-profesor. En este contexto, la UNATI/UFPE se destaca por promover e incentivar acciones para mejorar la calidad de vida de las personas mayores. La presente investigación es un relato de experiencia de la investigadora en el período en que era profesora en la UNATI/UFPE. El trabajo tiene por objetivo reflexionar sobre la utilización de material didáctico para clases de español para ancianos. A partir de observaciones hechas por la profesora y por algunas sugerencias de los propios alumnos a lo largo del curso, la profesora empezó a reflexionar sobre nuevas herramientas facilitadoras para la asimilación y aprendizaje de la lengua española en clase. En este sentido, la profesora intentó incorporar otros tipos de materiales didácticos, como los lúdicos, videos y canciones/canción, como forma de involucrar y motivar a los alumnos en las clases. De esta forma, la enseñanza de la lengua española en la UNATI/UFPE es una de las formas de empoderar a los ancianos. Se destaca así el uso del libro y la dificultad de envolvimiento de la clase a partir de éste, mostrándose necesario el uso de incorporación de nuevas técnicas para motivar a los alumnos.

Palabras-clave: Español. UNATI. Material didáctico.

\section{Introdução}

Diante de um cenário de crescente número de idosos em todo o mundo, pensar nesses sujeitos torna-se fundamental para a construção de um mundo apto para recebê-los, respeitando suas capacidades e dificuldades inerentes a idade.

Portanto, entre os vários contextos em que o idoso está inserido, é essencial pensa-lo no contexto educacional para que, com sua participação (atores sociais), seja possível construir um ambiente mais integrado, rompendo, assim, com diversos preconceitos que envolvem essa idade.

Dessa forma, a educação, mais especificamente, o ato de aprender por parte dos idosos, torna-se uma importante ferramenta de empoderamento na luta pelos seus direitos, da busca de uma nova forma de se socializar, de procura de aproveitamento de momentos de lazer, de desfrutar o aprendizado de uma nova língua, entre outras ocasiões prazerosas que a educação pode proporcionar.

Destaca-se a educação, por possibilitar que esses sujeitos tenham mais autonomia e independência, tanto no espaço individual como no social. Dentro desta, depreende-se o ensino da língua espanhola para idosos como forma de fortalecer as ferramentas já apontadas, além da troca de experiência entre aluno-professor.

Dentro desse contexto, a Universidade Aberta ao Idoso da Universidade Federal de Pernambuco (UnATI/PE) se destaca por promover e incentivar ações para melhoria da qualidade de vida das pessoas idosas, mediante a realização de cursos que facilitem a aquisição de novos conhecimentos e integração na sociedade contemporânea. (PROExC, 2016).

A presente pesquisa é um relato de experiência da pesquisadora no período em que 
era professora na UnATI/PE, no ano de 2016, com aulas com duração semestral e aulas as quartas-feiras, de 14:00 as 16:00, com conteúdo programático envolvendo desde gramática, conversação, leitura e compreensão auditiva e escrita. O trabalho tem por objetivo refletir sobre a utilização de material didático para classes de espanhol para idosos.

\section{Um Brasil de cabelos brancos}

A tendência mundial à diminuição da mortalidade e da fecundidade e o prolongamento da esperança de vida têm levado ao envelhecimento da população. O que era antes um fenômeno ligado a países e regiões desenvolvidas como Japão, Europa Ocidental e América do Norte, hoje ocorre também nos países do terceiro mundo, e as projeções estatísticas demonstram que esta é a faixa etária que mais crescerá na maioria dos países em desenvolvimento. (PASCHOAL; SALLES; FRANCO, 2006). Assim, esse fato que vem ocorrendo no Brasil e em outros países em desenvolvimento, desde a Segunda Guerra Mundial, é o que se convencionou chamar de "transição demográfica”. (CAMARANO, 2006; BELTRÃO; CAMARANO; KANSO, 2004).

Segundo o Instituto Brasileiro de Geografia e Estatística (IBGE), o crescimento da população de idosos é um fenômeno mundial, representando em 2002 um contingente de quase 15 milhões de pessoas com 60 anos ou mais de idade (8,6\%). Em 1998, o contingente era de 579 milhões de pessoas idosas no mundo. Projeções indicam que, em 2050, essa população idosa será de 1.900 milhão. Uma das explicações para esse fenômeno é o aumento, verificado desde 1950, de 19 anos na esperança de vida ao nascer em todo o mundo. Ainda no âmbito mundial, os números mostram que, atualmente, uma em cada dez pessoas tem 60 anos de idade ou mais. Nos próximos 20 anos, a população idosa do Brasil poderá ultrapassar os 30 milhões de pessoas e deverá representar quase $13 \%$ da população ao final deste período. (OLINO, 2006; BRASIL, 2013?; IBGE, 2002; KUNST, 2013).

Figura 1: Transição demográfica brasileira

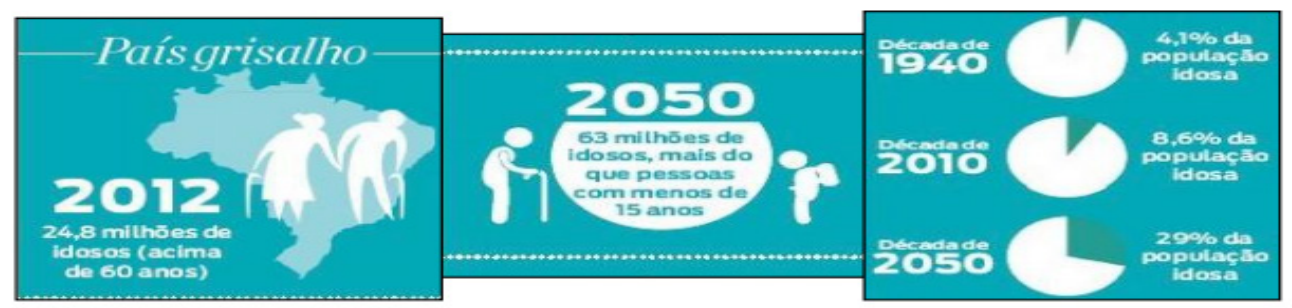

Fonte: NUNES (2014). Ver em: <http://revistaplaneta.terra.com.br/secao/ciencia/isso-e-que-e-melhor-idade>.

Estima-se que em 2020 os idosos representem $12 \%$ da população, o que em números absolutos corresponderá, aproximadamente, a 25 milhões de idosos. Estes, em 2025, deverão ser 32 milhões, sendo que, por volta de 2080, deverá ocorrer uma estabilização na proporção de idosos e jovens com, respectivamente, $15 \%$ e $20 \%$ do total de população. (PASCHOAL; SALLES; FRANCO, 2006). As projeções para o ano de 2040 indicam que 72 países terão 2 milhões ou mais de pessoas com 65 anos ou mais. (KINSELLA; HE, 2009).

Essa longevidade tem implicações importantes para a qualidade de vida, podendo trazer problemas com consequências sérias 
nas diferentes dimensões da vida humana, física, psíquica e social. (PASCHOAL, 2006). Com o envelhecimento, os aspectos fisiológicos do nosso organismo sofrem um processo de desgaste natural, e cada parte do corpo desacelera, desde a fala até o ritmo cardíaco, da velocidade do caminhar à rapidez de pensamento, do tempo de reação ao tempo de leitura. (HAZIN, 2012; BERGER, 2003).

Assim, o que se busca ao envelhecer é uma condição de vida boa, com o carinho e respeito da família, com a permanência das amizades adquiridas ao longo da vida, entre outros. O que se deseja é um envelhecimento saudável, repleto de boas lembranças e com um espaço para morar e ser bem aceito. No entanto, o envelhecimento acarreta várias condições inerentes à velhice, dentre elas a baixa da visão, redução auditiva, condição física mais debilitada, gerando várias limitações e consequências como, por exemplo, a utilização de muletas, andador, cadeira de rodas e outros. (KUNST, 2017).

\section{Breve história da língua espanhola no Brasil}

Devido à propaganda brasileira na Europa, e as guerras, além da falta de emprego na maioria dos países europeus, muitos imigrantes vieram ao Brasil em busca de melhores condições de vida. Na busca por manter sua cultura e tradições, muitos colonos deram uma grande importância ao ensino, e se organizaram para construir e manter escolas para seus filhos. (CARLOS; BORDINI, 2012).

Nesse aspecto, o espanhol passou a ser permitido oficialmente para compor o currículo do curso secundário, uma vez que não representava ameaça alguma para o Brasil, pois a quantidade de imigrantes vindos da Espanha era restrita. (CARLOS; BORDINI, 2012).
Na temática de aspectos sociopolíticos referentes à aprendizagem de uma língua estrangeira, evidenciamos a crescente ascensão do espanhol pela criação do MERCOSUL e pelo processo de globalização, tornando-se fundamental aos profissionais brasileiros com ambição de fazer carreira em multinacionais, em companhias de exportação ou de trabalhar com relações internacionais. (MORAIS, 2016).

Assim, Morais (2016) nos retoma a Lei de Diretrizes e Bases, de 1996, em que intitula a disciplina da língua estrangeira ser importante como qualquer outra do currículo, democratizando o seu acesso, abrangendo o tema de diversidade cultural ao ensino.

Para destacar o Brasil no MERCOSUL, foi criada em 2005, a Lei $n^{0} 11.161 / 2005^{1}$ que tornou obrigatória o ensino de espanhol nos estabelecimentos de Ensino Médio. Esta lei teve como fundamento de sua criação, os interesses políticos e econômicos, para melhorar as relações comerciais entre o Brasil e os países de língua espanhola. (CARLOS; BORDINI, 2012).

É importante ressaltar que o português e o espanhol possuem pontos em comum, de tal maneira que constituem uma classe de desenvolvimento da linguagem e o desenvolvimento da língua escrita, ou seja, a influência que o idioma estrangeiro exerce sobre o materno. Dessa forma, a aprendizagem de um língua estrangeira é de grande utilidade e proporciona ao sujeito aprendiz uma base, ademais de colaborar no desenvolvimento das habilidades na língua materna, aumentando

\footnotetext{
${ }^{1}$ Infelizmente revogada pela Lei $\mathrm{n}^{\mathbf{0}} \mathbf{1 3 . 4 1 5} / 2017$, que em seu artigo 3, parágrafo $4^{\circ}$ dispõe: “Os currículos do ensino médio incluirão, obrigatoriamente, o estudo da língua inglesa e poderão ofertar outras línguas estrangeiras, em caráter optativo, preferencialmente o espanhol, de acordo com a disponibilidade de oferta, locais e horários definidos pelos sistemas de ensino.” (BRASIL, 2017, n.p.).
} 
assim seus limites conceituais e promovendo o crescimento humano como um todo. De forma a evitar algumas interferências inadequadas de um idioma sobre o outro pela mistura das línguas (portunhol), por os dois idiomas serem considerados línguas irmãs - são derivadas do latim e semelhantes. (RIBEIRO; PARADA, 2015).

\section{Relato de experiência}

Entendendo que é na escola onde o professor é quem melhor conhece seus alunos, geralmente, o que se tem ao seu alcance, como forma de material didático para auxiliá-lo no processo de ensino/aprendizagem e no processo metodológico de sua aula, é apenas a utilização de livros didáticos (material que não é feito especificamente para o público idoso), o que leva, em certas ocasiões, a uma dependência excessiva ou a desmotivação dos alunos no decorrer do curso.

A partir desse fato e, de observações feitas pela professora e por algumas sugestões dos próprios alunos ao longo do curso, a professora começou a refletir sobre novas ferramentas facilitadoras para a assimilação e aprendizagem da língua espanhola em aula.

Isto ocorreu, pela visão da professora, primeiro pelo fato de que nas aulas estava tudo indo bem e pensando que os alunos queriam apenas aprender o espanhol, como uma forma de lazer, contudo estes tinham diferentes razões para aprenderem a língua, como futuras viagens, parentes no exterior ou o aprimoramento da mesma.

Diante desses acontecimentos, a professora tentou incorporar outros tipos de materiais didáticos, como os lúdicos (dominó customizado com palavras em espanhol e desenhos), vídeos (para apreensão e reforço de alguns assuntos da aula) e músicas/canção (como forma de ensinar ou reforçar algum conteúdo, gramatical ou não, de uma maneira mais lúdica e dinâmica), como forma de envolver e motivar os alunos nas aulas.

Visto que esse tipo de material, colocando o aluno em um papel ativo no ensino, proporcionando-lhe um grau mais elevado de interação e participação, damos-lhe maior motivação e interesse pelas atividades realizadas, torna possível estabelecer um ambiente em que os processos de ensino/aprendizagem sejam mais atraentes e participativos. (SILVA, 2015).

Porém, algumas expectativas da professora não foram supridas com a incorporação dessas ferramentas, visto que algumas barreiras também foram encontradas, tais como tarefas de casa não feitas e trabalhos em grupo, realizados em classe, em que não havia integração da turma. Para isso, Ribeiro e Parada (2015) apontam que os alunos tendem a criar uma insegurança, por não saber se estão falando corretamente a segunda língua escolhida por eles ou ainda se estão mesclando o espanhol com sua língua nativa (portunhol), aspecto amplamente exposto pela professora para não se preocuparem, pois estavam no momento de aprender.

Seguindo esse pensamento, Castro (2015) em sua revisão bibliográfica, aborda o tema de que os idosos demandam do professor, quanto ao conteúdo que domine o material, quanto ao aspecto pedagógico que se crie um bom clima, que se estruture boas aulas, que se faça exercícios práticos e que sejam simples. Já quanto as características pessoais, que o professor seja bom comunicador, que motive a turma, que seja entusiasta, que seja próximo a turma e que conheça as dificuldades que os idosos possuem.

É importante salientar, também, que um dos métodos utilizados é o comunicativo. Esse método, de base construtivista, acentua o uso da colaboração em grupo e motiva 
as práticas sociais interativas como eixo do aprendizado, deixando claro que a língua deve ser alvo de aprendizagem com vistas ao seu uso como fator de comunicação social. As aulas são marcadas pela participação ativa das alunas. Há ainda o método clássico de tradução, onde o aluno se baseia na tradução para a aquisição de língua estrangeira. (FARIA; MONTEIRO, 2007).

Dessa forma, é importante tomar em conta que o aluno não está inserido no contexto da língua estrangeira, tendo aulas só uma vez por semana, o que torna o esquecimento das aulas passadas muito comuns, além do surgimento da mistura do espanhol com a língua mãe. Portanto, cabe ao professor ajudar neste processo para nivelar esta desvantagem.

\section{Considerações finais}

O aumento da população idosa, verificado em todo o mundo, reivindica estudos específicos que possam contribuir para melhorar a qualidade de vida desse segmento da população, alterando o estigma do Brasil de país jovem. (KUNST, 2015).

Nesse contexto, a criação e manutenção de Universidades Aberta a Terceira Idade (UnATI ou UTI) desenvolveram a vocação de propiciar programas de lazer e programas educativos à população de adultos maduros, promover pesquisas visando à produção de conhecimentos acerca do processo de envelhecimento, formar profissionais para atuar na área de gerontologia, prestar serviços preventivos de saúde aos idosos e promover a integração entre as gerações. (CACHIONI, 1999).

Portanto, conclui-se que as UTIs são de grande sucesso, uma vez que vêm criando oportunidades de desafio intelectual e promovendo bem-estar a adultos maduros, que estão em busca de um envelhecimento bem-sucedido. Seus programas devem servir como espaço educacional, cultural e político, em que os alunos possam usufruir de uma vida mais saudável, participativa e produtiva nas sociedades em que estão inseridos. (GOMES; LOURES; ALENCAR, 2005).

Dessa forma, o ensino da língua espanhola na UnATI/UFPE é uma das formas de empoderamento presente nesse espaço proporcionado pela UFPE aos idosos. Salienta-se assim, o uso do material didático disponível (livro) e a dificuldade de envolvimento da turma a partir deste, mostrando-se necessário o uso de incorporação de novas técnicas para motivar os alunos.

Uma vez que, na maioria das vezes, os manuais disponíveis no mercado editorial não estão baseados em trabalhos que possibilite, de maneira efetiva, o processo de ensino e aprendizagem de língua estrangeira na perspectiva dos documentos e dos estudos feitos a nesse nível. (MORAIS, 2016).

Apesar disso, foi possível progredir ao longo do semestre, com o estimulo a participação dos alunos nas aulas, motivando-os a buscar textos, músicas e canções fora das aulas e, na medida do possível, tentando integra-los em aula para que juntos avançassem na aprendizagem do conhecimento.

Por fim, cabe destacar que ficou claro a produção de material didático específico para idosos, como forma de facilitar a disseminação do ensino e a facilitação da aprendizagem, além de ir ao encontro do art. 25, do Estatuto do Idoso, que informa que "[...] as instituições de educação superior ofertarão às pessoas idosas, na perspectiva da educação ao longo da vida, cursos e programas de extensão, presenciais ou a distância, constituídos por atividades formais e não formais.” (BRASIL, 2003, n.p.).

E também no seu parágrafo único, para apontar que o “[...] Poder Público apoiará a criação de universidade aberta para as pessoas 
idosas e incentivará a publicação de livros e periódicos de conteúdo e padrão editorial adequados ao idoso que facilitem a leitura considerando a natural redução da capacidade visual.” (BRASIL, 2003, n.p.).

\section{Referências}

BELTRÃO, K. I.; CAMARANO, A. A.; KANSO, S. Dinâmica populacional brasileira na virada do século $\mathrm{XX}$. Texto para discussão $\mathrm{n}^{\circ}$ 1.034. Rio de Janeiro: Ipea, 2004.

BERGER, K. S. O desenvolvimento da pessoa: da infância à terceira idade. Rio de Janeiro: LTC, 2003.

BRASIL. Lei $\mathbf{n}^{0}$ 13.415, de 16 de fevereiro de 2017. Disponível em: <http://www. planalto.gov.br/ccivil_03/_Ato20152018/2017/Lei/L13415.htm>. Acesso em 04 jul. 2017.

Secretaria Nacional de Promoção Defesa dos Direitos Humanos. Coordenação Geral dos Direitos do Idoso. Dados sobre o envelhecimento no Brasil. Brasília, 2013? Disponível em: <http://www.sdh.gov.br/ assuntos/pessoa-idosa/dadosestatisticos/ DadossobreoenvelhecimentonoBrasil.pdf>. Acesso em 04 jul. 2017.

Lei $\mathrm{n}^{0} \mathbf{1 0 . 7 4 1}$, de $1^{\circ}$ de outubro de 2003. Dispõe sobre o Estatuto do Idoso e dá outras providências. Disponível em: <http:// www.planalto.gov.br/ccivil_03/leis/2003/ L10.741.htm>. Acesso em 04 jul. 2017.

CACHIONI, M. Universidades da terceira idade: das origens à experiência brasileira. In: NERI, A. L.; DEBERT, G. G. Velhice e sociedade. Campinas: Papirus, 1999. p. 141178.

CAMARANO, A. A. Envelhecimento da população brasileira: uma contribuição demográfica. In: FREITAS, E. V. et al.(Orgs.). Tratado de geriatria e gerontologia. Rio de Janeiro: Guanabara Koogan, 2006. p. 88105.

CARLOS, V. G.; BORDINI, M. Ensino de língua estrangeira por meio de gêneros textuais: qual é a percepção dos professores em formação? Revista X, Curitiba, v. 1, n. 0, p. 1-23, jan./jun. 2012.

CASTRO, J. L. Los profesores de adultos mayores. Una revisión bibliográfica. Olhar de professor, Ponta Grossa, v. 18, n. 1, p. 30-43, jan./jun. 2015.

FARIA, F. S. C.; MONTEIRO, S. H. C. Desafios na terceira idade: o ensino de língua inglesa sob novas perspectivas. Instrumento - Revista de Estudo e Pesquisa em Educação, Juiz de Fora, v. 9, p. 29-33, jan./ dez. 2007.

GOMES, L; LOURES, M. C.; ALENCAR, J. Universidades abertas da terceira idade. Revista História da Educação, Pelotas, v. 9, n.17, p. 119-135, jan./jun. 2005.

HAZIN, M. M. V. Os espaços residenciais na percepção dos idosos. 2012. $143 \mathrm{f}$. Dissertação (Mestrado em Design) - Pósgraduação em Design, Universidade Federal de Pernambuco, Recife, 2012.

INSTITUTO BRASILEIRO DE GEOGRAFIA E ESTATÍSTICA. Perfil dos idosos responsáveis pelos domicílios. Rio de Janeiro: IBGE, 2002. Disponível em: <http://www.ibge.gov.br/home/presidencia/ noticias/25072002pidoso.shtm>. Acesso em 04 jul. 2017.

KINSELLA, K.; HE, W. An aging world: 2008 - international population reports (P95/09-1). Washington: Government Printing Office, 2009.

KUNST, M. H. Hotéis acessíveis para idosos(as): eles já existem. Um estudo de 
caso. 2013. 111 f. Monografia (Bacharelado em Economia Doméstica) - Departamento de Ciências Domésticas, Universidade Federal Rural de Pernambuco, Recife, 2013.

KUNST, M. H.; BRANDAO, J. S. Um sonho de casa acessível: o caso do Cidade Madura/ PB. In: CONGRESSO INTERNACIONAL DE ENVELHECIMENTO HUMANO, 5., 2017, Maceió. Anais eletrônicos..., Maceió: CIEH, 2017. Disponível em <http://editorarealize.com.br/revistas/cieh/ trabalhos/TRABALHO_EV075_MD2_ SA16_ID27_01062017114102.pdf >. Acesso em 04 jul. 2017.

KUNST, M. H.; SANTIAGO, M. de F. Hotéis e acessibilidade: uma forma de inclusão do idoso.In:CONGRESSOINTERNACIONAL DE ENVELHECIMENTO HUMANO, 4., 2015, Campina Grande. Anais eletrônicos..., Campina Grande: CIEH, 2015. Disponível em: < http://editorarealize.com.br/revistas/ cieh/trabalhos/TRABALHO_EV040_MD4_ SA8_ID232_26082015092843.pdf $>$. Acesso em 04 jul. 2017.

MORAIS, B. B. A utilização dos gêneros textuais para a leitura em espanhol: material didático e documentos oficiais. Cadernos de Pós-Graduação em Letras, São Paulo, v. 16, n. 1, p. 68-90, jan./jun. 2016.

NUNES, A. C. Isso é que é a melhor idade. Revista Planeta [online], São Paulo, n. 503, out. 2014. Disponível em: <https:// www.revistaplaneta.com.br/isso-e-que-e-amelhor-idade/>. Acesso em 04 jul. 2017.

OLINO, R. Quem é o idoso hoje? In: BERTELLI, S. B. O idoso não quer pijama!: aprenda a conhecer e como tratar esse novo cliente. Rio de Janeiro: Qualitymark, 2006.

PASCHOAL, S. M. P. Qualidade de vida na velhice. In: FREITAS, E. V. et al. (Orgs.).
Tratado de geriatria e gerontologia. Rio de Janeiro: Guanabara Koogan, 2006. p. 79-84. PASCHOAL, S. M. P.; SALLES, R. F. N.; FRANCO, R. P. Epidemiologia do envelhecimento. In: FILHO, E. T. C; NETTO, M. P. Geriatria: fundamentos, clínica e terapêutica. São Paulo: Atheneu, 2006. p. 19-34.

RIBEIRO, L.; PARADA, A. A. Tercera edad: un buen momento para aprender una lengua extranjera. Olhar de professor, Ponta Grossa, v. 18, n. 1, p. 11-19, jan./jun. 2015.

SILVA, J. E. N. Criação e crítica de materiais didáticos de italiano:(re) significação e (re) construção da abordagem comunicativa. In: BAALBAKI, A.; CARDOSO, J.; ARANTES, P.; BERNARDO, S. (Orgs.). Linguagem: teoria, análise e aplicações (8). Rio de Janeiro: UERJ: Programa de Pósgraduação em Letras, 2015. p. 207-218.

UNIVERSIDADE FEDERAL DE PERNAMBUCO. PROEXC. UNATI. 2016. Disponível em: <https://www3.ufpe.br/ proexc/index.php?option $=$ com_content $\& \mathrm{v}$ iew=article\&id=62\&Itemid=135> . Acesso em: 04 jul. 2017. 